\title{
EL IMPRESCINDIBLE ENSAYO SOBRE LAS ENFERMEDADES DE LA CABEZA (KANT, 1764)*
}

\section{THE INDISPENSABLE ESSAY ON THE DISEASES OF THE HEAD (KANT, 1764) María Noel Lapoujade**}

Universidad Nacional Autónoma de México

\begin{abstract}
Resumen: Esta Conferencia estudia el Ensayo sobre las enfermedades de la cabeza de Kant, 1764. El abordeaje se hace a partir de una descripción fenomenológica de las enfermedades psico-somáticas, entre otras, perturbaciones de la sensibilidad, patologías de la imaginación, las alucinaciones, alteraciones del raciocinio. La Conferencia se propone rescatar la vigencia y actualidad de la psicología filosófica kantiana y asimismo indicar de manera puntual la pertinencia del estudio del Ensayo como germen de las tres Críticas: Crítica de la razón pura, Crítica de la razón práctica y Fundamentación de la metafísica de las costumbres y la Crítica de la Facultad de Juzgar.
\end{abstract}

Palabras Clave: Descripción fenomenológica; perturbaciones mentales; alucinaciones; psicología filosófica; criticismo

\begin{abstract}
This lecture studies the Maladies of the Head essay by Kant, 1764. The approach is made through phenomenological description of psychosomatic diseases, among them troubles of sensitivity, pathologies of imagination, hallucinations, distortion of the power of reasoning. The lecture aims to rescue the validity and topicality of Kant's philosophical psychology and thus pointing out the relevance of the study of the Maladies as the seed of the three Critiques: Critique of Pure Reason, Critique of Practical Reason, Metaphysical Foundations and the Critique of Judgment.
\end{abstract}

Key Words: Phenomenological description; mental troubles; hallucinations; philosophical psychology, criticism

* (N. de la Ed.) Este Ensayo fue presentado en el V Coloquio Kant Multilateral celebrado en Madrid los días 9 al 12 de septiembre de 2014. Se publica bajo la autorización de la Sociedad de Estudios Kantianos en Lengua Española (SEKLE), por comunicación enviada a esta editorial con fecha 20 de marzo de 2015.

\section{Situación}

Es sintomático el que críticos, compiladores, traductores, investigadores y profesores de la filosofía kantiana suelen, o bien dejar a un lado o bien ignorar, o bien "no perder su tiempo" en este pequeño ensayo. Están ocupados en convertir a Kant en un adusto, seco, neurasténico, críptico y aburrido filósofo. Nada más falso, porque el Kant de carne y hueso no corresponde con esa imagen tan generalizada de nuestro filósofo. Una prueba de ello es, entre otros, este Ensayo fundamental.

¿Por qué es imprescindible el Ensayo sobre las enfermedades de la cabeza de Kant?

Este pequeño opúsculo contiene confesiones autobiográficas fundamentales, carac- terística del pensamiento de Kant que aflora en diversas obras y esporádicamente aún en las tres Críticas.

El Ensayo contiene unas críticas acerbas a la sociedad de su tiempo, a los médicos y al comportamiento humano en general.

En particular, Kant enfoca fundamentalmente los temas de la salud y la enfermedad mental, de lo normal y lo patológico.

En el Ensayo que nos ocupa se pone de manifiesto la aguda percepción y conocimiento de la psicología y el alma humana. Lo cual se prolonga especialmente en su Antropología del punto de vista pragmático y en su Lógica.

Ante la situación de facto que el Ensayo describe, se vuelve imperioso para Kant encontrar las salidas, proponer la brújula a un ser humano desorientado, corrupto, enfermo.

En general, el Ensayo adquiere una relevancia impactante porque en estas páginas

Correspondencia: Prof. Dra. María Noel Lapoujade. Universidad Nacional Autónoma de México.

Correo Electrónico: maria.noel.lapoujade@gmail.com 
es posible detectar la necesidad para Kant de escribir la Crítica de la Razón Pura (1960), La Crítica de la Razón Práctica (1975) y la Crítica de la Facultad de Juzgar (1961).

Este pequeño gran opúsculo muestra, además, el ignorado sentido del humor profundo, sutil y lúcido de Kant, esparcido sobriamente a lo largo de toda su obra aún en las Críticas.

\section{Propósito y estilo}

Su propósito explícito es, en última instancia, proceder a su propia catarsis, una limpieza de su propia triste disconformidad, su crítica acerba a la realidad social de su tiempo. Pero mucho más allá de ser un "escrito-desahogo", es una muestra valiosa del Kant humano, del Kant observador de su sociedad, que contiene en germen el pensamiento depurado del futuro Kant crítico.

Nietzsche sostiene que él ama los libros escritos con sangre; y bien, el Ensayo que nos ocupa es uno de ellos, expresa el desgarramiento kantiano en un estilo directo, coloquial, con un léxico que va desde las palabras comunes, hasta el argot, por momentos con tintes de lúcida crueldad (Nietzsche, 1994).

Kant traza según sus palabras una descripción empírica de las fallas de la cabeza y el corazón, surgidas de sus observaciones, con base en una premisa teórica fundamental.

\section{Premisas básicas}

Kant parte de la distinción entre el hombre en estado de naturaleza y el hombre cultivado, social, es decir, el que vive en la sociedad civil, el ciudadano, tesis de claro cuño rousseauniano.

La simplicidad y la sobriedad de la naturaleza no exigen del hombre y no forjan en él más que ideas comunes y de una honestidad grosera. La coacción artificial y la riqueza del estado de sociedad hacen surgir graciosos y elucubradores, pero también, en ocasiones, locos y bribones... (Kant, 1990: 49) ${ }^{1}$

El hombre, en el estado de naturaleza no le es casi posible devenir loco y difícilmente caer en la payasada. Sus necesidades lo retienen constantemente en la proximidad de la experiencia y dan a su entendimiento

1 Todas las traducciones del francés del Essai sur les maladies de la tête, Ensayo sobre las enfermedades de la cabeza de Kant son de la autora. que es sano, una ocupación tan ligera que el se da cuenta a penas que tiene necesidad de entendimiento en sus actividades (Kant, 1990: 70).

... lo más a menudo el está en buena salud porque es libre y puede moverse. Es en el estado de sociedad dónde se encuentran específicamente los fermentos de toda esta corrupción que los hombres, si no la producen, contribuyen a hacer durar y agrandar (Kant, 1990: 71).

La premisa que afirma la distinción: salvaje-civilizado, hombre natural-ser social, es problemática, y ha sido cuestionada en diversos sentidos. Fundamentalmente es poco fundada la noción básica de "salvaje" como natural, "no social", por contraposición a la noción de "civilizado", "culto", social. La antropología y la etnología desde fines del siglo XIX han puesto de manifiesto el carácter altamente refinado de las culturas, así llamadas arcaicas, con organizaciones sociales bien precisas.

Asimismo esta tesis tiene, a la vez, un núcleo de verdad comprobable. En culturas ancestrales como la antigua cultura china, hindú, egipcia, entre muchas más, así como en culturas actuales, vivas, "no occidentales", pienso en los aborígenes de Australia, Asia, América Latina, África, etc, las culturas más apegadas a la naturaleza, al cosmos y cuya vida se rige por los procesos cósmicos del cielo, la tierra, las estaciones, los días y las noches, los cuatro elementos, en general muestran una población en armonía con la naturaleza, con la vida misma de la tierra y cuyo funcionamiento tiene su propia legislación apegada a la vida misma.

Al mismo tiempo, las sociedades "cultas", "civilizadas" contemporáneas, en gran medida globalizadas y en el furor de las sociedades de consumo, muestran seres enfermos, sin equilibrio ni armonía, violentos, con imaginarios negros que llegan a determinar, entre otros, a las sociedades mismas. La desorientación existencial y ética, como asimismo la indiferencia generalizada por la naturaleza misma, las relaciones estéticas con la naturaleza, el cosmos, el otro, el carácter prácticamente obsoleto de escalas de valores que apunten a la vida y a la vida digna, vienen a confirmar a posteriori la tesis rousseauniano-kantiana (Lapoujade, 2006, 2009a, 2009b, 2010) En tal sentido sostiene que "el hombre degenerado se ha apartado de su lugar natural" (Kant, 1990: 55). El que se ha apartado de su lugar natural enferma. 
Kant en toda su obra, en particular en las Críticas se refiere al "sano entendimiento común", natural y al "sentido común", aún al "sentido común estético" (Kant, 1961).

Concretamente Kant es un agudo observador de la sociedad de su tiempo en general, y en particular de Königsberg².

\section{Salud-enfermedad}

El opúsculo enfoca temas fundamentales de la salud y la enfermedad, sobre todo en lo que respecta a lo anímico y mental. Estos temas caen en el dominio de la medicina, y son competencia de los médicos.

Por esta razón inicia la reflexión con una referencia a los médicos que, por lo demás, contiene una crítica aguda. Los médicos, asegura Kant, se dan por satisfechos con "asignar un nombre a la enfermedad" (Kant, 1990: 73). En la época actual considero que el problema se ha agravado, pues la medicina alopática ataca el síntoma con químicos que curan o aminoran el síntoma, pero destrozan otros órganos o funciones del organismo que los especialistas ven como zonas diversas, desarticuladas, casi "autónomas" y no como el organismo de un individuo considerado como una totalidad psico-somática.

\section{Primera parte. Fallas de la cabeza comunes en la vida social}

Kant procede a una interesante descripción de estas fallas comunes, comenzando por el individuo obtuso, mente cerrada, carente de espíritu. Lo distingue del tonto y del bobo, tonto por bondad. Ambas son formas de ingenuidad, en seres sin malicia, valores tan despreciados por la sociedad. Tanto es así que en la sociedad, en el lenguaje de los granujas, se desprecian esos individuos, y por el contrario se valoran los tramposos, avivados, hábiles para engañar, etc.

A estos especímenes sigue el hombre no razonable. Son los individuos cuya razón está encadenada por ejemplo, por las pasiones, en particular la pasión amorosa o la ambición y que, por ende, vive en la sinrazón.

Finalmente en la vida social están aquellos que se caracterizan por una especie de locura bufona. En ellos la razón parece haber sido puesta a la inversa, razo- nan al revés que el común de la gente. Kant considera que la locura bufona deriva de dos inclinaciones injustas: el orgullo y la avaricia. La ceguera del orgullo produce bufones estériles o inflados. La tacañería priva de todos los bienes, precisamente a quien quiere poseerlos todos. De manera que, según nuestro profundo observador de la psicología humana, es absolutamente imposible querer volver inteligente un bufón.

\section{Segunda parte. Enfermedades de la cabeza}

Se trata de casos graves que Kant clasifica en dos grupos: la impotencia mental, y el funcionamiento inverso de la mente en cuanto a las nociones, a los juicios y a los razonamientos.

Por impotencia mental Kant se refiere a los idiotas, en quienes considera, el cerebro está muerto.

En general el ordena las fallas del espíritu perturbado en tres tipos:

primero, la inversión de las nociones

empíricas...segundo el desorden en la

facultad de juzgar...tercero el trastocamiento

de la razón respecto de los juicios más

universales (Kant, 1990: 59) ${ }^{3}$.

Primero, en el análisis de la sensibilidad perturbada, Kant introduce desde esta obra temprana el papel fundamental de la imaginación humana, normal y patológica. Nunca insistiré lo bastante en la irrupción central de la imaginación en la obra de Kant, como un rompehielos en la historia de la filosofía occidental (Lapoujade, 1988).

\section{Imaginación y Sensibilidad}

El se apoya en la tesis del papel esencial de la imaginación humana, para el normal funcionamiento de la psique. En tal sentido reivindica de manera explícita y muy actual, la función de la imaginación en estos términos:

El alma de todo hombre, aún en buena salud, está ocupada en pintar toda suerte de imágenes de cosas inactuales, o a modificar, para cumplirlo la semejanza imperfecta a cosas en nuestras representaciones; y esto se hace gracias a tal o cual rasgo quimérico que nuestra facultad creativa y poética integra a la sensación (Kant, 1990: 60).

De inmediato lanza otra afirmación, que

3 Reiteramos este pasaje crucial en la relectura final, desde otro ángulo. Kant, id, p.59.

2 Ciudad de Prusia, lugar de nacimiento de I. Kant. 
coloca a Kant de un salto en plena filosofía contemporánea. Al respecto Kant reflexiona sobre vigilia y sueño, para sostener que la diferencia entre ellos es la vivacidad de las impresiones sensibles que vuelve oscuras las imágenes que la imaginación produce, en estado de vigilia. En el sueño, cuando la mente está "cerrada" a las impresiones exteriores, retoman el primer plano las imágenes. De modo que, en otras palabras, es preciso notar que en el sueño, la imaginación secretora de imágenes asume el papel protagónico.

Sin mucho hurgar evocamos a Freud y Bachelard entre las fuentes de tal concepción. Lo sorprendente es la lucidez kantiana para anticiparse a reflexiones uno o dos siglos posteriores a su obra. Concretamente se anticipa a Bachelard quien propone que la filosofía debe estudiar "el hombre de las 24 horas" como una totalidad integrada. Y bien Kant, en este pasaje reflexiona sobre "el hombre de las 24 horas" como una totalidad normal, sana. Otra faceta de la incuestionable vigencia y actualidad del pensamiento kantiano (Lapoujade, 2011 y 2014).

Pero Kant no se detiene aquí, sino que contempla los funcionamientos patológicos de la imaginación, que llamamos "imaginación patológica". En este campo el autor ubica con exactitud la alucinación. Los procesos alucinatorios a su vez pueden tener diversos "grados", desde el hombre que tiene ciertas alucinaciones particulares, al grado superior de aquel que vive en un mundo fantástico, fuera del entorno social.

En este sentido evoco los cuentos de Guy de Maupassant, entre otros, Le Horla (Lapoujade, 2009c: 33-37).

Entre las formas benignas, normales de crear imágenes autónomas a partir de lo real, Kant se refiere a las formas (imágenes) que se imaginan a partir de manchas en la pared, o de la disposición de las cortinas.

Cuando al despertar descansamos negligente y dulcemente distraídos, nuestra imaginación dibuja formas humanas a partir de las figuras irregulares de las cortinas...o de las manchas de un muro... (Lapoujade, 2009-3, 62).

Retomo esta referencia porque tiene una reflexión antecedente de singular importancia. Sin afirmar filiaciones ni influencias, sino coincidencias, evoco el pasaje del Tratado de la pintura de Leonardo da Vinci, donde el pintor describe casi con las mismas palabras esta posibilidad creadora para la imaginación pictórica. ${ }^{4}$

Es interesante poner énfasis en este asunto, pues se amplifica el alcance de la observación en cuanto su denotatum abarca, además, la creación pictórica.

Por otro lado, Kant señala con agudeza que la percepción no es "neutra", sino que cada uno, por así decir, ve lo que quiere ver, o su formación le permite ver. Evoco en William James un pasaje totalmente similar. Recupero ese breve pasaje del Ensayo:

Por otra parte es una ceguera común que hace que los humanos vean no lo que está allí, sino lo que su inclinación les presenta a los ojos: el naturalista ve ciudades en las piedras de Florencia; el hombre piadoso ve la narración de la Pasión en las manchas del mármol, tal dama ve en su lente la sombra de dos amantes bajo la luna, pero su cura ve allí dos campanarios" (Kant, 1990: 63).

Entre otras formas muy expandidas de imaginación patológica es la hipocondría, o de la imaginación lindante con la patología es la melancolía. Es importante señalar esta aportación de Kant como antecedente, a un tema central para el psicoanálisis: el capítulo de la melancolía, lo cual amerita un estudio específico. En este margen solamente baste la referencia, y una breve cita de Kant: "el melancólico es un fantasioso que se concentra sobre la desdicha de la vida" (Kant, 1990: 65).

Entre las alucinaciones más peligrosas Kant menciona al visionario o al extravagante, puesto que arrastra a otros seres a seguir sus fantasmagorías imaginarias. Este punto es el que Kant enfoca de manera central en Los sueños de un visionario, obra dirigida contra Swedenborg ${ }^{5}$, ejemplo de una larga y heterogénea lista de visionarios que se autoconsideran "místicos" o iluminados.

Segundo, siguiendo su propio esquema pasa a las perturbaciones del entendimiento, consistentes en formar juicios trastocados sobre datos sensoriales exactos. El primer grado de estas perturbaciones son los delirios, tristes o divertidos.

4 Leonardo da Vinci (1982): "Si observas algunos muros sucios de manchas o construidos con piedras dispares $y$ te das a inventar escenas, allí podrás ver la imagen de distintos paisajes, hermoseados con montañas, ríos, rocas, árboles, llanuras, grandes valles y colinas de todas clases" (p. 364).

5 Emanuel Swedenborg (1688-1772), científico y filósofo sueco. 
El segundo grado que Kant llama: aberración, consiste en estructurar juicios desequilibrados sobre conceptos universales. En estas mentes surgen perturbaciones por todo tipo de ideas demasiado sutiles.

Se trata de fallas de las funciones del conocimiento. Ellas culminan con la fallas de la razón, que dan como resultado razonamientos fallidos, ilógicos, perturbaciones que traban e impiden los procesos de conocimiento normales, formas de demencia.

Estas formas de perturbaciones del entendimiento, la facultad de juzgar y la razón, según Kant, muy difícilmente atañen al hombre en estado natural, sino que se manifiestan demasiado frecuentemente en estado de sociedad civil. (Kant, 1990).

El hombre en estado natural, sostiene Kant tiene buena salud porque "es libre y puede moverse":

es en el estado de sociedad que se encuentran específicamente los fermentos de toda esta corrupción... El entendimiento en la medida en que provee a las necesidades y a las satisfacciones simples de la vida, es un entendimiento sano; pero en la medida en que es requerido por el lujo y el artificio, sea en el orden del gozo o de las ciencias deviene un entendimiento refinado. (Kant, 1990: 73).

Finalmente Kant enfoca la enfermedad del corazón, consistente en "la ruina de la voluntad" (Kant, 1990: 73).

\section{Relectura del Ensayo como germen de las tres Críticas}

El opúsculo es una suerte de matraz en el que las Críticas van emergiendo en el espíritu de Kant como una necesidad para sus contemporáneos y para el ser humano en general.

Por un lado, las enfermedades del corazón, "ruina de la voluntad", muestran a Kant la necesidad de buscar y crear salidas posibles. $Y$ bien, en este sentido la K.p.V, y la Gr. ${ }^{6}$ ofrecen esa salida, son brújulas orientadoras para la humanidad perdida.

Desde las primeras páginas desde este opúsculo-observatorio el nota que "cada uno es mucho más celoso de los privilegios del entendimiento que de la buena cualidad de la voluntad y comparando estupidez y engaño nadie dudaría un instante en pronunciarse a favor de la última" (Kant, 1990: 50).

6 En referencia a las "Críticas..." de I. Kant.
Poco después agrega "las trampas y los artificios engañadores se transforman en la sociedad civil en máximas habituales..." (Kant, 1990: 52).

Dada esa situación de facto, Kant crea la Crítica de la Razón Práctica y la Fundamentación de la Metafísica de las Costumbres, como brújulas orientadoras de las fallas de la voluntad humana la cual ciertamente no es una "voluntad santa", y comienza a precipitar el "imperativo categórico" como contrapartida universal de la subjetividad arbitraria de las máximas de la acción. Esta obra cardinal para la ética de todos los tiempos, vigente hoy más que nunca, no está pensada como un puro ejercicio formal, una ética vacía, formal, sino una ética (metalenguaje) que permita orientar las diversas morales (lenguaje de objeto), relativas, culturales, históricas, sociales (Lapoujade, 2014b).

Más aún, en el Ensayo Kant constata que la voluntad humana se mueve en gran medida por pasiones, inclinaciones. En tal sentido afirma:

Las pulsiones de la naturaleza humana, que se llaman pasiones, cuando alcanzan grados importantes, son las fuerzas motrices de la voluntad... (Kant, 1990: 53)

Es decir, en la acción se trata de una voluntad heterónoma, que es la que está determinada por pasiones tales como la ambición y la pasión amorosa; o inclinaciones como el orgullo y la avaricia, que atenazan la voluntad y le quitan la libertad. De manera que, dada esta situación humana de hecho, se hace necesario para Kant establecer una posibilidad para que la voluntad humana se desencadene, con miras a pensar en un ser humano libre y digno. Así, adquiere espesor significativo la ley de la autonomía de la voluntad, según la cual la razón prescribe a la voluntad: "sé libre", independízate de las inclinaciones determinantes. En tal sentido Kant enuncia la ley de la libertad de la voluntad. Por otro lado, en los opúsculos sobre Filosofía de la Historia, Kant clama por la necesidad de un ser humano erguido, con una razón libre.

Por otro lado, el Ensayo contiene las señales de alerta para su propio autor, de la necesidad de crear una Crítica de la Razón Pura y una Crítica de la Facultad de Juzgar.

Entre las sagaces observaciones de la naturaleza humana, el Ensayo contiene un párrafo que condensa en pocas líneas el origen de la necesidad de una Crítica de la Razón Pura, 
y una Crítica de la Facultad de Juzgar. Kant, como apuntamos, ordena las enfermedades de la cabeza en función de tres distinciones, según que las fallas provengan de la sensibilidad, de la facultad de juzgar o de la razón. He aquí el germen de las ulteriores fenomenologías de la sensibilidad, el entendimiento, la facultad de juzgar y la razón. El pasaje dice así:

Creo poder ordenar (las fallas del espíritu) por las tres distinciones siguientes: primero, la inversión de las nociones empíricas... segundo, el desorden introducido en la facultad de juzgar ... tercero, la perturbación de la razón respecto de los juicios... (Kant, 1990: 59).

En lo que sigue describe en ese orden cada una de ellas. Notemos que ese orden de la descripción empírica, psicológica del Ensayo, es el mismo orden de la fenomenología de la razón pura que es la Crítica de la razón pura: sensibilidad (percepto), entendimiento (concepto-juicio), razón en sentido estricto (razonamiento). En ella, dicho sea de paso, desde el punto de vista lógico, Kant sigue, con las diferencias conocidas, el orden de la lógica aristotélica, concepto-categorías, juicio (relaciones aseverativas entre conceptos), razonamientos (inferencias inmediatas y mediatas).

Finalmente, el Ensayo dedica un breve pero sustancioso pasaje a la relación entre locura y genio. Este pasaje esboza lo que en la K.U. se encuentra desarrollado en la teoría del genio, el creador, el artista, el poeta.

Al respecto asienta un comentario germinal, puesto que considera que en los grandes genios "la razón en su lentitud no puede seguir el espíritu que se rebela" (Kant, 1990: 69).

Este enunciado es un indicio de lo que será en la Crítica de la Facultad de juzgar, su teoría del genio. Si este término provoca resistencias, podemos llamarlo teoría del creador, el artista. En esta obra que inaugura una estética completamente válida en nuestro presente, Kant elabora una teoría del creador, el artista auténtico. Ello en función de la relación de las funciones o facultades del espíritu que están en juego en la creación artística. En los márgenes de este texto me limito a evocar dos o tres puntos claves: primero, el artista, el creador es el que "da la regla al arte", en otras palabras, crea escuela, crea perspectiva nueva, no sigue escuelas o tendencias ya constituidas. Este es el genio, el que introduce una nueva tendencia.
Segundo, el artista es capaz de volver visible lo invisible, lo suprasensible. Así, por ejemplo, las numerosas representaciones de Dios, Cristo, la Virgen María, María Magdalena, el Espíritu Santo, la Anunciación, el juicio final, o la libertad, la justicia etc, en la Historia de la pintura occidental (Kant, 1961: parágrafo 49).

Esto es posible porque la imaginación produce las figuras, las configuraciones visibles de lo invisible. En otras palabras, la imaginación vuelve sensible las ideas, las cuales por definición son conceptos de la razón, sin correlato empírico. (Dios, la inmortalidad del alma, la libertad).

En este sentido Kant afirma con precisión y belleza que la imaginación, en cuanto función de configuración, de exposición, su actividad "ensancha el alma" (Kant, 1961: 122).

En fin, Kant, anticipándose a Nietzsche en El filósofo como médico de la civilización, considera que para una posible cura, el filósofo "podría ordenar la dieta del espíritu" (Kant, 1990: 74-75).

En este pequeño gran texto que es el Ensayo, nuestro inefable Kant muestra una veta fundamental de su espíritu, demasiado frecuentemente soslayada, porque su espíritu expresa su extrema lucidez con un mordaz sentido del humor.

\section{Sentido del humor}

\section{¿Qué entender por humor?}

En su Crítica de la Facultad de Juzgar Kant da una noción pertinente del humor en cuanto "significa el talento de ponerse voluntariamente en cierta disposición de ánimo en que todas las cosas se juzgan de modo muy distinto y aún opuesto que de ordinario" (Kant, 1961: 188-189).

Es interesante subrayar que su precisa noción de humor, lo señala como una actitud de espíritu, que separa los aspectos insólitos de una situación, con cierta toma de distancia, una perspectiva sobre el asunto, que sitúa a quien lo ejerce más allá del acontecimiento, en el cuál no se involucra. El humor reviste diversas formas tales como la ironía, el sarcasmo, la sátira, el humor negro etc. En general, conlleva más o menos velada, una crítica incisiva de la situación. Solamente 
pensando levemente estas nociones concluimos que el espíritu de Kant está habitado por un profundo y sagaz sentido del humor del que nuestro Ensayo da muestras elocuentes.

(El sabio es) aquel que es sin locura. Este sabio se le puede buscar, por ejemplo, en la luna, puede ser que en ese lugar uno es sin pasión e infinitamente razonable (Kant, 1990: 55).

Es decir, el sabio no existe.

Para terminar, con una sonrisa, dejemos resonar en nuestros espíritus los ecos de este pasaje insuperable de Kant:

...la cabeza humana es verdaderamente un tambor que resuena porque está vacía (Kant, 1990: 50-51).

¿Será por eso que sigue resonando hoy en nuestras cabezas el inigualable Ensayo sobre las enfermedades de la cabeza?

\section{Referencias}

Da Vinci, L. (1982). Tratado de la pintura. Madrid: Editora Nacional.

Kant, I. (1960). Crítica de la Razón Pura. Buenos Aires: Losada.

Kant, I. (1975). Crítica de la Razón Práctica. Madrid: Espasa - Calpe.
Kant, I. (1961). Crítica de la Facultad de Juzgar. Buenos Aires: Losada.

Kant, I. (1990). Ensayo sobre las enfermedades de la cabeza. París: G. F. Flammarion.

Nietzsche, F. (1994). Así habló Zarathustra. La Flèche (France): Gesamtherstellung (Clásicos Alemanes, 39).

Lapoujade, M. N. (1988). Filosofía de la imaginación. México: Siglo XXI.

Lapoujade, M. N. (2006). De la perversión a la violencia natural, en Revista de Filosofia núm. 54. Maracaibo: Universidad de Zulia.

Lapoujade, M. N. (2009a). De las cárceles de los imaginarios a una estética de la libertad, en Revista Iberoamericana de Comunicación núm. 15, Mexico: Universidad Iberoamericana-UNESCO.

Lapoujade, M. N. (2009b). Una estética de la salud, en Revista Realidad núm. 119. San Salvador: Universidad Centroamericana José Simeón Cañas.

Lapoujade, M. N. (2009c). La seducción de una filosofía radical en Guy de Maupassant, en Revista de Filosofía núm. 114. San José: Universidad de Costa Rica.

Lapoujade, M. N. (2010) De l'esthétique en perspective à l'existence esthétique, en Esthétiques de l'espace, Occident et Orient, J. J. Wunenburger et V. Tirloni (comps.). París: Mímesis.

Lapoujade, M. N. (2011). Diálogo con G. Bachelard acerca de la poética. Mérida: Universidad Nacional Autónoma de México.

Lapoujade, M. N. (2014a). Propuesta bachelardiana acerca de la objetividad, en Revista de Filosofía núm. 133. San José: Universidad de Costa Rica.

Lapoujade, M. N. (2014b). Reflexiones acerca de las realidades en que habitamos. Madrid: Sociedad de estudios kantianos en lengua española (SEKLE).

\footnotetext{
** María Noel Lapoujade, uruguaya. Su formación ha sido un rico camino que ha discurrido entre sus estudios doctorales en Filosofía en la Universidad Nacional Autónoma de México (México) y los que realizó en la Universidad de París (Francia). Inquieta y con tantas preguntas para las buscó y aun busca respuestas, realizó estudios post doctorales en Filosofía Francesa Contemporánea en la U. de Paris, con becas de la UNAM y en Filosofía en la U. de Heidelberg. Alemania, con beca del DAAD.

Profesora titular full time de Posgrado y Grado en Filosofía (UNAM). Dictó cursos y conferencias en Brasil, Cuba, Costa Rica, Chile, Colombia, México, Uruguay, Argentina, Paraguay y en Francia.

Investigadora en el Centre Gaston Bachelard de la U. de Bourgogne, Francia (2003-05).

Fundadora del Centro Interdisciplinario de Estudios sobre lo Imaginario y la Racionalidad y del Seminario interdisciplinario de investigación sobre lo imaginario (UNAM); del Programa interdisciplinario de investigación sobre la imaginación, lo imaginario y la racionalidad, PROIM. Fundadora de la Maestría en Estética y Artes, U. de Puebla, México.

Premios: "Norman Sverdlin" y Medalla Gabino Barreda, por la UNAM. Condecorada "La Dama de las Hespérides", por el Ateneo de Murcia., España. "Tributo al pensamiento Nacional", Uruguay, 2013.

Múltiples libros y artículos publicados en Francia, Alemania, Italia, Bulgaria, Rumania, Estados Unidos, México, Costa Rica, Brasil, Venezuela, San Salvador y Uruguay. Traducida al inglés, del francés al portugués, al rumano, al búlgaro, al italiano.

Incluida como filósofa latinoamericana del siglo XX en el Biographical Dictionary of Twentieth Century Philosophers, publicado por la Routledge Editorial en Londres y New York. Incluida como filósofa lationamericana en Identidad, Integración y Creación cultural en América Latina.

Publicaciones sobre: El desafío del Mercosur. UNESCO, Editorial de Belgrano, Argentina. Espacios Imaginarios. Compiladora. FFYL UNAM, (Universidad Nacional Autónoma de México). Memorias del Primer Coloquio Internacional de Estética ,1997. Imagen, Signo y Símbolo, Compiladora. FFYL- BUAP. México. 2000. Memorias del Segundo Coloquio Internacional de Estética, 1999. Tiempos Imaginarios: ritmos y ucronías, Compiladora. FFYL-BUAP. México. 2002. Memorias del Tercer Coloquio Internacional de Estética, 2001. Homenaje por la Facultad de Filosofía y Letras, UNAM, 2012. Homenaje por la Asociación Filosófica del Uruguay, AFU, 2013.
}

Para citar esta Conferencia:

Lapoujade, M. N. (2015). El imprescindible ensayo sobre las enfermedades de la cabeza, 1764 Kant. Ciencias Psicológicas 9(1): 107 - 113 